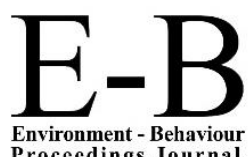
Environment - Behaviour
Procecdings Journal
AIVCE-BS-2, 2020ShahAlam

https://www.amerabra.org; https://fspu.uitm.edu.my/cebs; https://www.emasemasresources.com/ AMEABRA International Virtual Conference on Environment-Bahaviour Studies, ${ }^{\text {nd }}$ Series cE-Bs, FSPU, Universiti Teknologi MARA, Shah Alam, 02-03 Dec 2020

\title{
Urban High-Density Living Effects on Mental Health
}

\author{
Nur Masyitah Ghazali1 , Marlyana Azyyati Marzukhi², \\ Oliver Ling Hoon Leh², Raja Norashekin Raja Othman² \\ ${ }^{1}$ Centre of Graduates Studies, Faculty of Architecture, Planning and Surveying, \\ Universiti Teknologi MARA, Shah Alam, Malaysia \\ ${ }^{2}$ Centre of Studies for Town and Regional Planning, Faculty of Architecture, Planning and Surveying, \\ Universiti Teknologi MARA, Puncak Alam, Malaysia
}

masyitah.ghazali@gmail.com, marlyana@uitm.edu.my, oliver3979@uitm.edu.my, rnora747@uitm.edu.my Tel : +60166798143

\begin{abstract}
Urban living has rapidly become a highly important due to the increasing rate of mental health problems worldwide. Most people in the urban area live in high-density residential due to limited spaces, land, and higher cost of living. The objectives are to study how urban high-density living environments can affect mental health and the contributing factors to mental health problems. This study was carried out at low-cost flats in Pudu, located in the Federal Territory of Kuala Lumpur. The findings show that urban high-density living environments can become a contributing factor to mental health problems in various ways.
\end{abstract}

Keywords: Urban environment; density; mental; health

eISSN: 2398-42870 2020. The Authors. Published for AMER ABRA CE-Bs by e-International Publishing House, Ltd., UK. This is an open access article under the CC BYNC-ND license (http://creativecommons.org/licenses/by-nc-nd/4.0). Peer-review under responsibility of AMER (Association of Malaysian Environment-Behaviour Researchers), ABRA (Association of Behavioural Researchers on Asians) and cE-Bs (Centre for Environment-Behaviour Studies), Faculty of Architecture, Planning \& Surveying, Universiti Teknologi MARA, Malaysia.

DOI: https://doi.org/10.21834/ebpj.v5i15.2462.

\subsection{Introduction}

Mental disorder is a health condition that involves either in the ways of thinking, emotions, and one's behaviour or the combinations of these which can affect a person's difficulties to cope with their daily life routine. The mental disorder also can be in various severity from mild to extremely severe, and some people also may have mental disorder undiagnosed by the medical experts due to lack of awareness of the community. It is worrisome based on data from Institute for Health Metrics and Evaluation (2018), Malaysia has the highest percentage of people having mental disorders among Southeast Asia countries which are 3.52 per cent in 2017 and inclining trend. As for our neighbouring country percentage such as in Singapore is 3.44 per cent, Thailand is 3.09 per cent, Indonesia is 2.64 per cent, and Brunei has 2.56 per cent. Anyone can have mental disorder since childhood to adulthood, and it is a long-term health problem, especially to those who are left untreated.

As mental disorders cases in Malaysia also worrying as most of these problems were in urban areas, and the prevalence is household income category of Below 40\% (B40) compared to Middle 40\%(M40) and Top 20\% (T20). According to Malaysia National Health and Morbidity Survey 2019 (MNHMS 2019), the prevalence of depression among children and adults is higher in the B40. In urban areas, most of B40 category area living in high-density residentials which is in low-cost flats. Other than that, the increasing trend of urbanisation and people living in urban areas also cause many high-density housings being built. In Malaysia context, the expected number of urban populations by the year 2040 is 46.1 million (3rd National Physical Plan,2016) which means the provision of housing

eISSN: 2398-4287O 2020. The Authors. Published for AMER ABRA cE-Bs by e-International Publishing House, Ltd., UK. This is an open access article under the CC BYNC-ND license (http://creativecommons.org/licenses/by-nc-nd/4.0). Peer-review under responsibility of AMER (Association of Malaysian Environment-Behaviour Researchers), ABRA (Association of Behavioural Researchers on Asians) and cE-Bs (Centre for Environment-Behaviour Studies), Faculty of Architecture, Planning \& Surveying, Universiti Teknologi MARA, Malaysia.

DOI: https://doi.org/10.21834/ebpj.v5i15.2462. 
need to be sufficient to accommodate this amount. With the limited area of land and various types of land uses, high-density housing is one of the most suitable options in providing adequate housing to the people in urban areas. The aim of this study is to the effect of living in urban high-density residential. Thus, the objective of this research is to study and analyses the conditions of mental health among urban high-density residents, especially for common mental disorder (depression, anxiety, and stress).

\subsection{Literature Review}

The urbanisation that has an increasing trend worldwide can affect the urban environment, population, and density. Besides, urbanisation is not only found to be associated with higher morbidity rates (Zock et al., 2018) but also increasing rates of some mental disorders problems (Flisher and Chalton, 2001). According to Sundquist (2004), the higher level of urbanisation is associated with the increased rates of psychosis and depression for both men and women. Urbanisation creates pressure on the development in the urban area, which causes more high-density housing to suffice the number of the growing urban population. Limited spaces, resources, and high cost of living, causing the low-income group to live in low-cost high-density housing. There are loads of evidence that high density can affect both physical and mental health.

\subsection{High-density living and Mental Health}

Housing area includes the environment, housing conditions, density, and spaces. A safe, conducive, and sufficient space for living is important because the home is a place to relaxing and release from fatigue. Environmental characteristics such as housing, crowding, noise, indoor air quality and light have a direct effect on mental health (Evans, 2003). The physical environment of a home also can affect directly and indirectly the self-esteem and psychological well-being through lack of social contact (Thomas et al., 2017). Highdensity low-cost housing in the urban area commonly for below $40 \%$ of income distribution or B40 due to the cost of living and most of this group could not afford a better quality of housing, as Bentley et al. (2011) stated that poor housing affordability could affect to risk of mental health problems. Low socioeconomic status causing people to live in an unsafe and deprived neighbourhood which can give direct and indirect effects on mental health (Xiao et al., 2018). Low socioeconomic status is highly related to the low-income group which resides in high-density low-cost housing in urban area due to limited resources and not many choices. Friesinger et al. (2019) suggested that housing location and the quality of the neighbourhood are important for people's well-being, especially people with mental health. People with low socioeconomic status in urban area are living in a low-cost high-density area which is normally in a deprived area and could not choose the housing preferences based on their comfortability due to financial restriction.

The location of housing will determine the accessibility and facilities provided. Meanwhile, Rautio et al. (2017) suggested housing with a well-planned environment, good quality, sufficient green spaces, and low levels of noise and air pollution can prevent mental health problems such as depression. It is supported by Hoisington et al. (2019), the quality of low-cost housing in urban areas such as crowding, noise, dark conditions, and structural quality has a risk for depression especially to women. Wang et al. (2018) summarised that a good location and housing condition could improve both physical and mental health. However, as the urbanisation level is increasing, the number of population in urban areas also will increase, which causing limited spaces and location for a proper housing provision. According to a study by Wong et al. (2016) in Hong Kong, the evidence of a significant effect of living neighbourhood and mental health is also contributed by household size and property age. Living in high-density housing with an in-house crowding has a stronger effect on mental health compared to in-house crowding of low-density housing (Evans et al., 2002). Overcrowding has become a significant factor in mental health problems in housing; Firdaus (2017) stated that overcrowding restricts physical and emotional spaces and creates a hindrance in developing supportive social relationships within the households. Overcrowding in a smaller space is a common problem in low-cost high-density living because the residents could not afford a higher cost of living. Qiu et al. (2019) and Evans et al. (2001), in his study, found that neighbourhood floor area ratio and building density has a positive correlation with mental health. Building density, in house crowding and quality of housing, may become the contributing factors to mental health problems, especially in the urban areas. This study investigates several questions related to high-density living environments such as crowding, spaces and residents feeling especially in Malaysia low-cost high-density area.

\subsection{Methodology}

This study aims to analyse the relationship between urban high-density living with mental health; thus the selected study area is near to the Commercial City Centre (CCC) of the Federal Territory of Kuala Lumpur which is in Pudu. Other than that, the Pudu area is the earliest low-cost flats built in the Federal Territory of Kuala Lumpur. The selected flats are Flat Hang Tuah built in 1967 and Flat Sri Selangor built in 1972. Both of these flats has around 500 to 650 square feet of units with one and two bedrooms. These flats are located near to the public transportation station and surrounded by a commercial centre. Both selected study area is high-density and in a crowded area. This character of the selected area is based on the housing density, the location of the housing, and the housing spaces.

\subsection{Questionnaire Survey and Respondents Sampling}

This survey conducted using Depression, Anxiety, Stress Scales (DASS-21) which is the shorter version of DASS-42. DASS-21 questionnaire consists of self-reported scales designed to measure the emotional states of depression, anxiety, and stress. This survey using the adaptation of the DASS-21 checklist to achieve the aim and objectives of this study which is focusing on the respondents feeling in living spaces and the environment. The questionnaire is four-point Likert scaled items that require the respondents to indicate their assessment to measure states of depression, anxiety, and stress. 
The total of 102 respondents from a total population of 6,120 for both Flat Hang Tuah and Flat Sri Selangor is selected based on $92 \%$ of confidence intervals using the Raosoft Sample Size Calculator. The sampling method is using homogenous sampling, which the respondents were chosen based on their sharing characteristics of locality but covers the various demographic background. The respondents were chosen randomly and represent the total population of the area and may have mental health problems or without mental health problems. Collected data is analysed by using the IBM SPSS Software to conduct the correlation analysis.

\subsection{Finding and Discussion}

Data collected consists of both male and female and varies academic qualifications, employment status, and household income. This survey is to analyse the respondent's socioeconomic status, which is also related to the urban high-density low-cost living. From data on table 1, the number of male respondents is $47.1 \%$, and female is $52.9 \%$. From the total respondents, only $47.1 \%$ are employed. Meanwhile, $25.5 \%$ are unemployed, and $25.5 \%$ is a housewife. The unemployed reason is due to old age, health problems, and no job opportunities.

Table 1. Respondent's socio-demographic background

\begin{tabular}{ll}
\hline Variables & Percentage \\
\hline Gender & \\
& \\
Male & 47.1 \\
Female & 52.9 \\
Academic Qualification & \\
Primary School & 26.5 \\
Secondary School & 62.7 \\
Higher Education & 4.9 \\
None & 5.9 \\
Employment Status & \\
Employed & 47.1 \\
Student & 2.0 \\
Housewife & 25.5 \\
Unemployed & 25.5 \\
Household Income & \\
Below RM 1,000 & 61.8 \\
RM 1,001 - RM 3,000 & 36.3 \\
RM 3,001 - RM 6,000 & 2.0 \\
\hline
\end{tabular}

From table 2, most of the respondents completed secondary school (62.7\%), and most of this group having a household income below RM1,000 (33.3\%). From table 2 also, it shows that $26.5 \%$ of the respondents completed primary school, and most of this group also has a below RM1,000 of household income (20.6\%). From this table, it shows that most of the respondents living in the study area having a below RM1,000 household income which is insufficient for urban living.

Table 2 Respondents Academic Qualification and Household Income

\begin{tabular}{lllll}
\hline Academic & \multicolumn{3}{c}{ Household Income (\%) } \\
Qualification & Below RM 1,000 & RM 1,001-RM 3,000 & RM 3,001-RM 6,000 & Total \\
\hline Primary School & 20.6 & 5.9 & 0 & 26.5 \\
Secondary School & 33.3 & 27.5 & 2.0 & 62.7 \\
Higher Education & 2.0 & 2.9 & 0 & 4.9 \\
None & 5.9 & 0 & 0 & 5.9 \\
Total & 61.8 & 36.3 & 2.0 & 100.0 \\
\hline
\end{tabular}

The density of person per acre for Flat Hang Tuah is 779 , meanwhile for Flat Sri Selangor is 1,077 (refer table 3) based on the number of units in the selected area. However, the density, as stated in Kuala Lumpur City Plan 2020, whereas the density is 400 person per acre. The population density for the total area is high and dense if compared to the density guidelines. The number of people living in the units is also overcrowded. Based on the survey conducted, the highest number of persons living in one unit is 10 person which $1.0 \%$. Most of the respondents living alone, which is $25.5 \%$, however, $20.6 \%$ of the respondents living in the units with 4 persons. Most of the units are 1 -bedroom flats, and $25 \%$ of the units are 2 -bedrooms.

Table 3 Residential Density

\begin{tabular}{llllll}
\hline Location & Acreage & No. of Floor & No. of Units & Units Size (sqft) & Density (Person per acre) \\
\hline Flat Hang Tuah & 2.62 & 17 & 408 & 500 & 779 \\
Flat Sri Selangor & 7.58 & 17 & 1,632 & 650 & 1.077 \\
\hline
\end{tabular}

\subsection{Depression, Anxiety and Stress}

The result of the respondent's state of mental health is self-reported scales using DASS-21. The severity of mental health is summarised in Table 4. Results in Table 4 show that more than half of the respondents are having symptoms of depression, anxiety, and stress. From the results, a person can experience more than one type of mental health problem at a time. The total number of male respondent's experience depression, anxiety, and stress (23.5\%) is slightly higher than female respondents $(22.5 \%)$. However, the number of female respondents having anxiety is higher (6.9\%) than male respondents $(2.0 \%)$. Other than that, female respondents also experience a 
higher percentage of anxiety and stress which is $3.9 \%$ rather than male respondents which are $2.0 \%$. The total of respondents having depression, anxiety, and stress overall is $74.6 \%$ which is more than half, and it is very worrying. From the analysis, only $25.4 \%$ of respondents do not have any symptoms of mental health problems. These results are based on the respondent's feelings in their living environments and its surrounding. Many factors are contributing to this problem, and living environments are one of the factors that may contribute to mental health, either directly or indirectly. To study the factors that can contribute to mental health through the urban environment, a correlation analysis is conducted to find the relationship between urban high-density living with mental health problems.

Table 4 State of severity for mental health status

\begin{tabular}{lllllll}
\hline Types & Male & \multicolumn{3}{c}{ Temale } & \multicolumn{3}{c}{ Total } \\
& Nos & $\%$ & Nos & $\%$ & Nos & $\%$ \\
\hline Normal & 13 & 12.7 & 13 & 12.7 & 26 & 25.4 \\
Depression & 3 & 2.9 & 3 & 2.9 & 6 & 5.8 \\
Anxiety & 2 & 2.0 & 7 & 6.9 & 9 & 8.9 \\
Stress & 1 & 1.0 & 1 & 1.0 & 2 & 2.0 \\
Depression and Anxiety & 2 & 2.0 & 2 & 2.0 & 4 & 4.0 \\
Depression and Stress & 1 & 1.0 & 1 & 1.0 & 2 & 2.0 \\
Anxiety and Stress & 2 & 2.0 & 4 & 3.9 & 6 & 5.9 \\
Depression, Anxiety and Stress & 24 & 23.5 & 23 & 22.5 & 47 & 46.0 \\
Total & $\mathbf{4 8}$ & $\mathbf{4 7 . 1}$ & $\mathbf{5 4}$ & $\mathbf{1 0 0 . 0 0}$ & $\mathbf{1 0 2}$ & $\mathbf{1 0 0 . 0 0}$ \\
\hline
\end{tabular}

\subsection{Urban High-density and mental health correlation}

A correlation analysis is conducted to find the relationship between depression, anxiety, and stress with the feeling of respondents when in their living area. From the correlation analysis, it is shown that a positive and significant correlation between the respondent's positivity feeling in their living area with depression, anxiety, and stress. Difficulty in having a positive feeling in their neighbourhood area can lead a person to depression. From this analysis, the relationship could not experience a positive feeling with depression has a strong correlation at a 0.01 level. This feeling also has a medium correlation with anxiety and stress at a 0.01 level which means it can also contribute to anxiety and stress. This feeling differs to how a person experience in their neighbourhood area, it may be caused by the respondents feeling not safe when they are at their neighbourhood and number of criminal cases of the area is worrisome. It also can be caused due to lack of social or community support to the respondents, which makes them feel alone and has negative feelings towards the neighbourhood environments.

Table 5 Correlation between urban high-density neighbourhood with mental health

\begin{tabular}{lllll}
\hline Justification & & Depression & Anxiety & Stress \\
\hline Could not experience the positive feeling & Coefficient $(r)$ & $0.545^{\star *}$ & $0.343^{* *}$ & $0.382^{* *}$ \\
when at a neighbourhood area & Significant $(p)$ value & 0.000 & 0.000 & 0.000 \\
$\begin{array}{l}\text { Excessively rapid breathing, breathless in } \\
\text { the absence of physical exertion at a }\end{array}$ & Coefficient $(r)$ & $0.287^{* *}$ & $0.531^{* *}$ & $0.457^{* *}$ \\
neighbourhood area & Siginificant $(p)$ value & 0.003 & 0.000 & 0.000 \\
\hline
\end{tabular}

Correlation analysis is also being conducted for respondents experiencing excessively rapid breathing or breathlessness without any physical exertion when they are staying in their neighbourhood area. From the analysis, it is found that the person experiencing excessively rapid breathing has a positive and strong correlation with anxiety at the 0.01 level. This feeling shows a person with anxiety problems. Other than that, it also shows a medium correlation with the symptoms of a person having stress. Anxiety can cause panic attacks which makes a person experience excessive rapid breathing without any physical activities; thus it is showing that the respondents feeling when they are in their neighbourhood area cause them to experience anxiety and panic attacks. Home is supposed to become a place where a person can feel safe, to rest from fatigue and stress at works, and a place to relax during days and night. However, from the results, it shows that the respondents are having problems of could not relaxing at home and feeling agitated when at their own house. It can contribute to a person feeling stress and lead to anxiety and depression when they could not feeling comfortable in their own spaces.

\begin{tabular}{lllll}
\multicolumn{5}{c}{ Table 6 Correlation between respondent's living spaces with mental health } \\
\hline Justification & & Depression & Anxiety & Stress \\
\hline Feeling agitated when at home & Coefficient $(r)$ & $0.536^{* *}$ & $0.381^{* *}$ & $0.591^{* *}$ \\
& Siginificant $(p)$ value & 0.000 & 0.000 & 0.000 \\
Difficulty to relax at home & Coefficient $(r)$ & $0.601^{* *}$ & $0.401^{* *}$ & $0.617^{* *}$ \\
& Siginificant $(p)$ value & 0.000 & 0.000 & 0.000 \\
Felt down-hearted and blue when at home & Coefficient $(r)$ & $0.657^{* *}$ & $0.333^{* *}$ & $0.470^{* *}$ \\
& Significant $(p)$ value & 0.003 & 0.000 & 0.000 \\
Feeling scared without good reason when & Coefficient $(r)$ & $0.445^{* *}$ & $0.504^{* *}$ & $0.362^{* *}$ \\
at home & Siginificant $(p)$ value & 0.003 & 0.000 & 0.000 \\
\hline
\end{tabular}

In order o study more on the respondents feeling when living in the urban high-density environment, a correlation analysis is conducted to find the relationship between depression, anxiety and stress with the respondents feeling when in their own living spaces. Based on table 6, four items are analysed, which is their feeling when at their own house. The analysis shows the positive and significant results of respondents feeling agitated and difficult to relax when they are in their own living spaces. A strong correlation and significant 
value at 0.01 level between these two items with depression and stress, which is meaning that they could not relax in their own spaces. Living spaces should be the place that people could rest and release from fatigue and stress. However, if a living space could not become a place to relaxing, it can lead to stress and depression to a person. Other than that, when a person is feeling down-hearted and blue when they are in their own living space, it is a symptom of depression. From the analysis in table 6 , a positive and significant correlation is shown for respondents feeling down-hearted and blue when at their home with the depression. To analyses the correlation between living spaces with anxiety, respondents were asked whether they experience feeling scared without any good reason when they are at their own homes. As a result, it shows a positive and significant correlation with a value of 0.01 level. Feelings scared without good reasons when staying at home show a strong correlation with anxiety; thus, the person who experiences this may having anxiety and depression. When a home which is considered as private spaces and should be comfortable to its residents has become the place or spaces that give tenses and stress to them when they are feeling unsafe and feeling scared in a sudden without any good reason, it shows that the respondents might be experiencing from anxiety. It could lead to depression and other mental health problems. These findings demonstrate the importance of living spaces to a person because it can affect their psychological well-being in various ways.

\subsection{Conclusion}

From the data analysed, it shows that the living environment and spaces can contribute to mental health either directly or indirectly. It can be evidence that high-density living and crowded living spaces have a relationship with mental health problems. The significant relationships show between respondents' own living spaces and neighbourhood areas can affect their feeling and mental health conditions. The living spaces in an urban area with a safe and conducive environment is important as people need spaces and safety to run their daily routine. High-density, crowding, and smaller spaces can affect some people that already with mental health problems and also can become a cause for some people. As the number of people will moving to the urban area increased by the year, it is important to ensure safe and sufficient spaces to avoid the rates of mental health problems to increase. Low-cost housing development should consider the location, provided spaces for living and socialising, and safety of its residents to ensure all residents could have a balanced mental and physical well-being through the environments. However, the survey conducted area self-reported scales; it can cause bias. A longitudinal study is suggested for further studies on the relationship between urban high-density living affect mental health in various scopes such as through social interaction, floor level living, green and recreational spaces, and location of the residential area.

\section{Acknowledgements}

The authors would like to express our gratitude to the Faculty of Architecture, Planning and Surveying, Universiti Teknologi MARA (UiTM), and Ministry of Higher Education Malaysia through Fundamental Research Grant Scheme (600-IRMI/FRGS 5/3 (063/2019) for their generous contribution towards this research.

\section{Paper Contribution to Related Field of Study}

Previous research has shown various related studies on the relationship between the built environment and mental health since the 1970s. This research could become additional evidence on the relationship between urban environment and mental health, especially regarding high-density and overcrowding spaces. Apart from that, it also can be referenced for a further and more detailed studies to proves how urban environment through density could affect mental health and factors towards it.

\section{References}

Bentley, R., Baker, E., Mason, K., Subramaniam, S., \& Kavanagh, A. M. (2011). Association between housing affordability and mental health: A longitudinal analysis of a nationally representative household survey in Australia. American Journal of Epidemiology, 753-761.

Evans, G. W. (2003). The Built Environment and Mental Health. Journal of Urban Health: Bulletin of the New York Academy of Medicine, 536-555.

Evans, G. W., Lercher, P., \& Kofler, W. W. (2002). Crowding and children's mental health: the role of house type. Journal of Environmental Psychology, 221-231.

Firdaus, G. (2017). Built environment ad health outcomes: Identification of contextual risk factors for mental well-being of older adults. Ageing International 42, 62-77.

Flisher, A. J., \& Chalton, D. O. (2001). Urbanisation and Adolescent Risk Behaviour. South African Medical Journal (91)(3), 243-244.

Friesinger, J. G., Topor, A., Bøe, T. D., \& Larsen, I. B. (2019). Studies regarding supported housing and the built environment for people with mental health problems: A mixed-methods literature review. Health and Place $57,57,44-53$.

Gary W. Evans, S. S. (2001). Residential Density And Psychological Health Among Children In Low-Income Families. Environment and Behavior, 165-177.

Hoisington, A. J., Steams-Yoder, K. A., Schuldt, S. J., Beemer, C. J., Maestre, J. P., Kinney, K. A., Postolache, T.T., Lowry, C.A., Brenner, L. A. (2019). Ten questions concerning the built environment and mental health. Building and Environment 155, 155, 59-69. 
Qiu, Y., Liu, Y., Liu, Y., \& Li, Z. (2019). Exploring the Linkage between the Neighborhood Environment and Mental Health in Guangzhou, China. International Journal of Environmental Research and Public Health, 16(3206), 1-15.

Rautio, N., Filatova, S., Lehtiniemi, H., \& Miettunen, J. (2017). Living environment and its relationship to depressive mood: A systematic review. International Journal of Social Psychiatry, 1-12.

Sundquist, K., Frank, G., \& Sundquist, J. (2004). Urbanisation and incidence of psychosis. British Journal of Psychiatry, 293-298.

Thomas, H., Weaver, N., Patterson, J., Jones, P., Bell, T., Playle, R., . . Araya, R. (2007). Mental Health and Quality of Residential Environment. British Journal of Psychiatry, 500-505.

Wang, S., Cheng, C., \& Tan, S. (2018). Housing determinants of health in urban China: a structural equation modelling analysis. Social Indicators Research, 1-26.

Wong, C. S., Chan, W., Lam, L. C., Law, W., Tang, W., Wong, T., \& Chen, E. Y. (2016). Living environment and psychological distress in the general population of Hong Kong. Procedia Environmental Sciences, 78-81.

Xiao, Y., Miao, S., Sarkar, C., Geng, H., \& Lu, Y. (2018). Exploring the Impacts of Housing Condition on Migrants' Mental Health in Nanxiang, Shanghai:A Structural Equation Modelling Approach. 15(225).

Zock, J.-P., Verheij, R., Helbich, M., Volker, B., Spreeuwenberg, P., Strak, M., Janssen, N.A.H, Dijst, M., Groenewegen, P. (2018). The impact of social capital, land use, air pollution and noise on individual morbidity in Dutch neighbourhoods. Environmental International 121, 453-460. 